\title{
Overall survival after resection for colon cancer in a national cohort study was adversely affected by TNM stage, lymph node ratio, gender, and old age
}

\author{
Kristian E. Storli • Karl Søndenaa • Ida R. K. Bukholm • Idunn Nesvik • Tore Bru • \\ Bjørg Furnes • Bjarte Hjelmeland • Knut B. Iversen • Geir E. Eide
}

Accepted: 3 May 2011 / Published online: 12 May 2011

(C) The Author(s) 2011. This article is published with open access at Springerlink.com

\begin{abstract}
Background A national surveillance program of colon cancer treatment was introduced in 2007. We examined prognostic factors for colon cancer operated in 2000 with an aim of improving survival in the new program and a special focus on the merit of lymph node yield.

Methods A cohort of 269 patients, 152 women (56.5\%), with a mean age of 71 years, was operated for colon cancer in 2000 at three teaching hospitals and followed up for 7 years.

Results Overall 5-year survival was $58.0 \%$, and overall hospital mortality was $5.2 \%$, with $4.5 \%$ in elective cases and $12.5 \%$ after urgent surgery. In only $41.1 \%$ of the
\end{abstract}

K. E. Storli $\cdot$ K. Søndenaa $(\bowtie) \cdot$ B. Furnes $\cdot$ B. Hjelmeland $\cdot$

K. B. Iversen

Department of Surgery, Haraldsplass Deaconal Hospital,

University of Bergen,

PO Box 6165, 5892 Bergen, Norway

e-mail: kasoende@online.no

\section{K. Søndenaa}

Department of Surgical Sciences, University of Bergen,

Bergen, Norway

I. R. K. Bukholm

Department of Surgery, Akershus University Hospital,

Oslo, Norway

I. Nesvik • T. Bru

Department of Surgery, Stavanger University Hospital,

Stavanger, Norway

G. E. Eide

Centre for Clinical Research, Haukeland University Hospital,

Bergen, Norway

\section{G. E. Eide}

Department of Public Health and Primary Care,

University of Bergen,

Bergen, Norway specimens were 12 or more lymph nodes retrieved, but this did not affect survival in the combined cohort, although one of the hospitals achieved a significantly better result with a harvest of 12 or more lymph nodes. In a multivariate analysis, old age, gender, a high lymph node ratio (LNR) at stage III, and tumor-node-metastasis stage were adverse factors for survival.

Conclusions The operative mortality was high and should be reassessed. The lymph node count did not have a significant impact on outcome overall, whereas the LNR proved significant for stage III. A prospective protocol using overall lymph node yield as a surrogate measure for more radical surgery, nevertheless, seems warranted to improve the lymph node harvest according to international recommendations.

Keywords Colon cancer - Lymph nodes · TNM stage · Surgery · Survival

\section{Introduction}

In recent years, the results after surgery for rectal cancer in Norway, with a 5-year overall survival (OS) rate of $60.1 \%$, has surpassed that of colon cancer at $57.5 \%$ [1]. This has been achieved because the surgical technique has been standardized according to total mesorectal excision (TME) with subsequent dramatic reductions of local recurrences. Beginning in 2007, all colon cancers were to be reported separately to the Norwegian National Cancer Registry in an effort to systematically survey and hopefully improve results. Nevertheless, a national strategy to standardize surgical treatment along the lines of radical surgery has neither been implemented in detail nor been generally accepted $[2,3]$. 
In this respect, the number of lymph nodes retrieved may act as a surrogate measure of radical surgery. The survival benefit of a large lymph node harvest has been shown in several reports [2-4]. It has been accepted nationally to offer patients with tumor-node-metastasis (TNM) stage III below a certain age, usually 75 years, adjuvant chemotherapy. This depends on adequate staging and lymph node sampling. It has been decided that a rather arbitrary level of 12 retrieved nodes is enough to obtain adequate surgery and staging. Pathologists may be a key factor for optimal lymph node harvest, and a conjoined effort between surgeon and pathologist would be ideal to improve results [2-6].

The aim of the study was to examine, after modest radical colon surgery removing mesocolic nodes and focus on lymph node yield, what would influence survival and where surgical improvement might be possible using data from a cohort of patients from three large Norwegian teaching hospitals.

\section{Material and methods}

Patients from a national cohort were operated in 2000, and follow-up was until December 2007, a mean of 7.5 years later. Three teaching community hospitals, Haraldsplass Deaconal Hospital, Stavanger University Hospital, and Akershus University Hospital contributed patients.

\section{Surgery}

All three hospitals are teaching community hospitals, and the patients were operated with an open access by a large number of surgeons. At that time, extra radical surgery was unusual, and it is fair to assume that radical surgery usually constituted a moderate mesocolic resection. If metastases were diagnosed, patients and tumor conditions were assessed regarding feasibility for resection.

\section{Follow-up}

Patients usually went to the outpatient clinic every third month for the first 2 years and then every sixth month until 5 years had passed. Blood tests with carcinoembryonic antigen measurement and ultrasonography of the liver and chest X-ray were carried out. Elderly patients are stead-bound and even if a few of them were not followed up frequently, they could be tracked and life status ascertained through their identity number in the official National Population Registry. Death certificates for all deceased patients were available through Statistics, Norway.
Pathology

The specimen was examined and rinsed by the surgeons on the back table before being mounted on a board and placed in a box filled with enough formaldehyde for secure fixation. The specimen was examined by a junior pathologist; after $48-72 \mathrm{~h}$, assisted by the consultant. Lymph nodes were harvested by sight and palpation. A minimum sampling of 12 lymph nodes was aimed for. Tissue was paraffin-embedded, and hematoxylin-eosin staining was used routinely before sections were examined microscopically. Metastatic deposits were defined as lymph nodes if these structures resembled nodes but without containing visible lymphatic tissue. The large intestine was defined as ending $16 \mathrm{~cm}$ from the anus. The TNM classification 5th edition was used for staging.

\section{Oncology}

Patients younger than 75 years of age that were classified as TNM stage III were offered 12 courses of adjuvant treatment with 5 -fluorouracil plus calsiumfolinate (FLV).

\section{Ethics}

The Regional Committee for Medical and Health Research Ethics of Western Norway and the Data Inspectorate for National Registries approved the study. The study is part of a prospective project registered with clinicaltrials.gov (NCT00963352).

\section{Statistical analysis}

The chi-square test was used to compare groups with respect to categorical variables and analysis of variance for continuous variables. The following variables were analysed with respect to survival: hospital, age, gender, location, no of lymph nodes and lymph node ratio (LNR), T stage, and TNM stage. Survival curves were estimated by the Kaplan-Meier method [7] and compared using the logrank test [8]. Multiple prognostic factors were analysed with the Cox proportional hazards model [9] using the SPSS 17 package.

\section{Results}

Two hundred sixty-nine patients, $152(56.5 \%)$ women and 117 men, with a mean age of 71 years (range, 20-93 years) were studied. One of the hospitals operated male patients that were younger, with a mean of 67 years. 


\section{Surgery}

The different tumor locations are shown in Table 1. Tumor locations were not different between the hospitals $(p=0.059)$. Right hemicolectomy and sigmoid resection were the most common procedures $(78.4 \%)$. Locoregional R0 resections for a single tumor location were done in 264 patients, while double resections $(n=4)$ and a suspected locoregional R1 resection $(n=1)$ were done in five patients.

Pathology

There were no significant differences between hospitals relating to TNM stage distribution: 34 patients (12.6\%) were stage I, 116 patients (43.1\%) were stage II, 93 patients (34.6\%) were stage III, and 26 patients $(9.6 \%)$ were stage IV. The number of lymph nodes harvested for various stages were 8.7 (stage I), 10.3 (stage II), 10.9 (stage III), and 10.3 (stage IV). In 11 patients, the pathologist had classified the T category and TNM stage but omitted to specify the number of lymph nodes present. The mean number in 258 patients was 10.3 lymph nodes per specimen. Twelve or more lymph nodes were examined in $41.1 \%(106 / 258)$ of the resected specimens. Significantly fewer lymph nodes $(p<0.001)$ were harvested at one of the hospitals. Otherwise, the three patient populations had similar characteristics.

\section{Survival analysis}

Overall in-hospital mortality was 5.2\% (14/269; range, $4.3-$ $6.3 \%)$. Urgent surgery had a mortality of $12.5 \%(3 / 24)$, whereas the elective group had a mortality of $4.5 \%$ (11/
245). The 5 -year OS was $58.0 \%$ (Fig. 1) and did not differ between the hospitals (log-rank $p=0.372$; Fig. 3).

Whether categorizing number of lymph nodes harvested in three groups $(<10,10-19,20$ or more $)$ or in two $(<12,12$ or more), no differences was found in OS (log-rank $p=0.423$ and 0.270 , respectively). This was still the case after adjusting for hospital or TNM stage (log-rank $p=0.449$ ). The uncategorized number of lymph nodes was not significant in a simple Cox regression (likelihood ratio $p=0.129$ ). However, in one hospital, better survival was found when the lymph node harvest was $\geq 12$ compared to $<12(\log$-rank $p=0.037)$ as shown in Fig. 2. Stage II patients had OS of $72.7 \%$ with $\geq 12$ nodes harvested and $58.3 \%$ with $<12$ nodes ( $p=0.124)$, and stage III patients had a 5 -year OS of $61.5 \%$ and $55.6 \%$, respectively $(p=0.508)$.

In stage III patients, the lymph node ratio (LNR) was highly significant for patient survival, and OS for LNR 1 $(<0.25)$ was $83.3 .5 \%$, LNR $2(0.25-0.50) 63.3 \%$, LNR 3 (0.51-0.75) 18.8\%, and LNR 4 (0.76-1) 18.2\% (log-rank test $p<0.001)$. The total number of lymph nodes was not significant for stage III patients.

Two of the hospitals did more resections of T4 tumors (chi-square test $p=0.021$ ). Adjusted for hospital, T4 tumors compared to T1-T3, was a significant adverse factor for survival in the log-rank test $(p=0.049)$.

Survival according to the different TNM stages is shown in Table 2. The 5-year OS was $58.1 \%$ for stage III and $63.8 \%$ for stage II without differences between the hospitals in uni- and multivariate analyses. OS for stage IV was significantly worse $(p<0.001)$.

The results of univariate and multivariate Cox-regression analyses are shown in Table 3. In the univariate Cox regression old age, T category, high LNR, and TNM stage
Table 1 Tumor locations and pathology variables of patients resected for colon cancer at three teaching community hospitals in 2000

${ }^{a}$ Resection of two tumors in separate locations

${ }^{\mathrm{b}}$ No radical loco-regional tumor resection

\begin{tabular}{lcc}
\hline Variables & $\begin{array}{l}\text { All patients } \\
n=269\end{array}$ & $\begin{array}{l}\text { Chi-square test } \\
p \text { value }\end{array}$ \\
\hline Location & $115(42.8)$ & 0.059 \\
Right hemicolon & $44(16.4)$ & \\
Transverse colon including flexures & $9(3.3)$ & \\
Descending colon & $96(35.7)$ & \\
Sigmoid colon and rectosigmoid & $5(1.9)$ & \\
Multiple or R1-2 $^{\mathrm{b}}$ & & \\
T category & $11(4.1)$ & \\
T1 & $30(11.2)$ & \\
T2 & $180(66.9)$ & \\
T3 & $48(17.8)$ & \\
T4 & $34(12.6)$ & \\
TNM stage & $116(43.1)$ & \\
I & $93(34.6)$ & \\
II & $26(9.7)$ & \\
III & & \\
IV & & \\
\hline
\end{tabular}




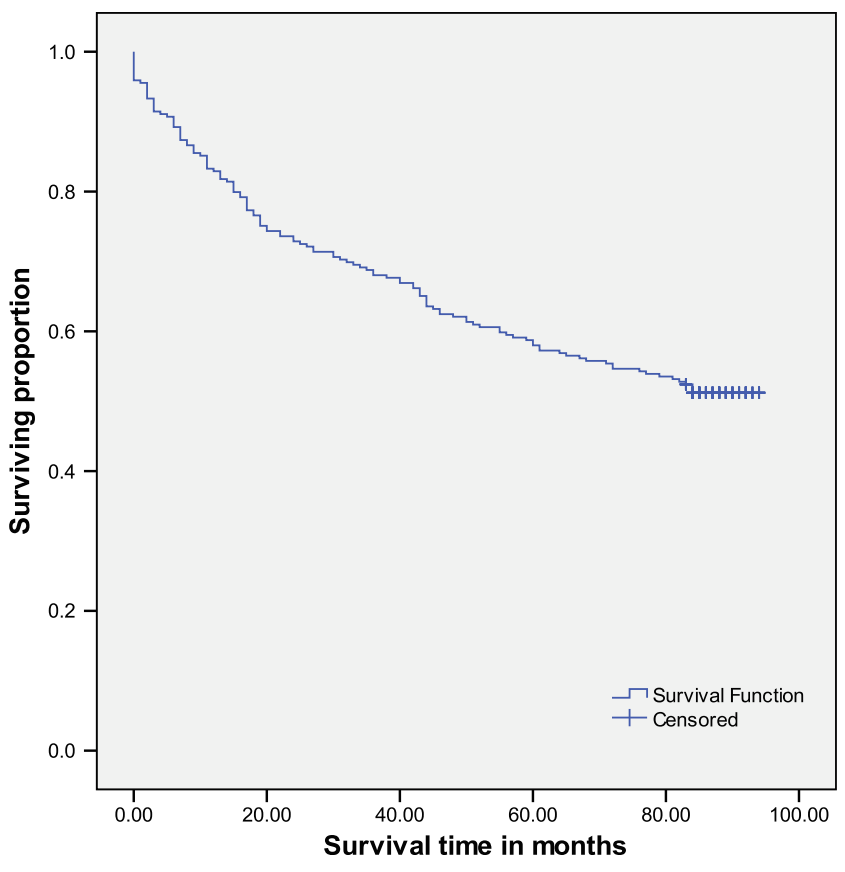

Fig. 1 Kaplan-Meier survival curve for 269 patients resected for colon cancer in three Norwegian hospitals in 2000

were adverse factors for survival. Age as a variable was highly significant both as a continuous variable and with a cutoff value of 69 years. Locations of the tumors with regard to the various resected segments were not significant (Table 3).

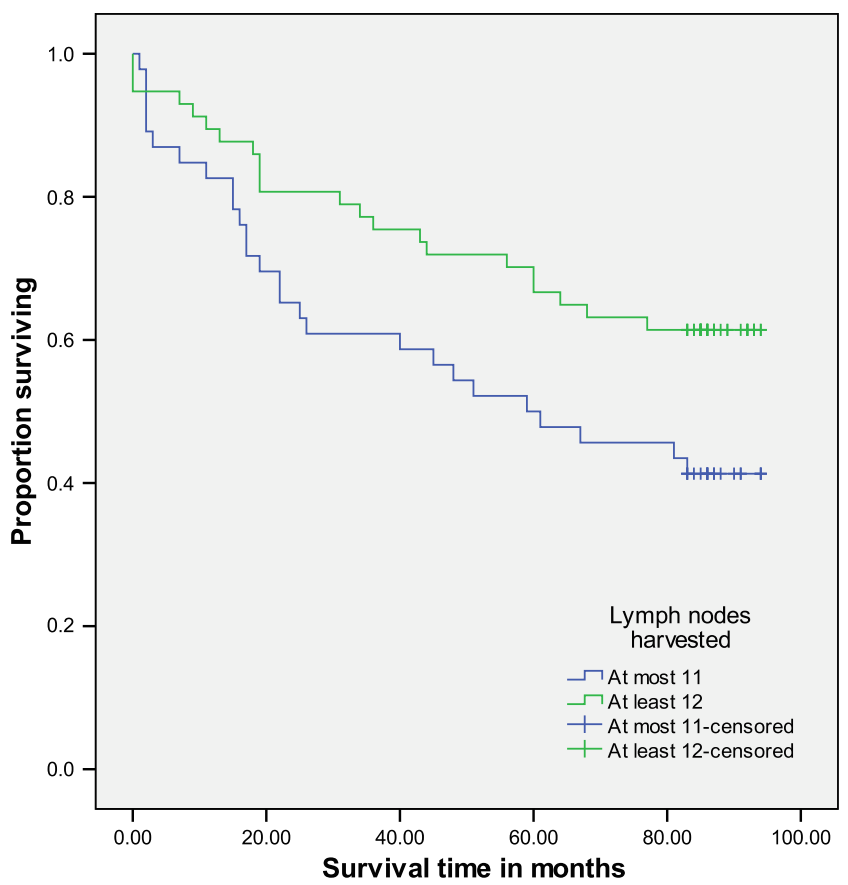

Fig. 2 Kaplan-Meier survival curve for 103 patients resected for colon cancer in one of three Norwegian hospitals in 2000. Patients with a lymph node harvest of 12 or more showed significantly better overall survival (log-rank test $p=0.037$ )
Table 2 Five-year overall survival (OS) according to the different TNM stages for 269 patients treated with resection for colon cancer in three Norwegian teaching community hospitals in 2000

\begin{tabular}{lcr}
\hline TNM stage & $n(\%)$ & $\%$ OS \\
\hline I & $34(12.6)$ & 76.5 \\
II & $116(43.1)$ & 63.8 \\
III & $93(34.6)$ & 58.1 \\
IV & $26(9.7)$ & 7.7 \\
All stages & $269(100)$ & 58.0 \\
\hline
\end{tabular}

In the multivariate model age, male gender, high LNR, and TNM stage were adverse factors (Figs. 4, 5, and 6). In the fully adjusted multivariate analysis, $\mathrm{T}$ category was not significant, but when removing TNM stage from the multivariate model, the $\mathrm{T}$ category again became significant $(p=0.047)$. These variables were not significant: hospital, tumor location, or number of harvested lymph nodes in these categories $(<10,10-19, \geq 20)$. LNR was also highly significant for stage III patients $(n=93)$ when adjusted for all the variables in Table 3 in a multivariate Cox regression with HRs (95\% CIs) of $1.72(0.80,3.67), 5.16$ (2.48, $10.74)$, and $4.80(1.92,11.99)$ for LNR $2-4$ vs. LNR 1 , respectively $(p<0.001)$.

\section{Statistical analysis}

The study may have been underpowered for detection of an assumed difference between patients with a lymph node harvest of $<12$ lymph nodes and those with $>12$. With the number of patients included in our study, a power of at least 0.84 would be necessary to detect a difference in 5-year survival of $50 \%$ vs. $68 \%$. An increase in sample size to detect a difference of $50 \%$ vs. $60 \%$ with a power of 0.80 in a one-tailed chi-square test would require 305 patients in each group.

\section{Discussion}

Even though several groups have pioneered radical surgery for colon cancer (complete mesocolic excision and a central tie) with its potential benefits similar to (TME) of rectal cancer surgery, such an approach has not been widely adopted in our country. Therefore, we wanted to examine our background results based on a less standardized approach and potential areas for improvement before embarking on more radical procedures as championed by others [2].

The 5-year overall survival (OS) for all three hospitals was $58.0 \%$. Advanced TNM stage had an adverse influence on outcome, as the results for stage IV versus I-III and 
Table 3 Univariate $(n=269$ patients) and multivariate $(n=258)$ Cox regression models for analysis of overall survival for patients resected for colon cancer in three Norwegian teaching community hospitals in 2000

\begin{tabular}{|c|c|c|c|c|}
\hline & $\begin{array}{l}\text { Univariate } \\
\text { HR 95\% CI }\end{array}$ & $p$ value & $\begin{array}{l}\text { Multivariate }^{a} \\
\text { HR } 95 \% \text { CI }\end{array}$ & $\begin{array}{l}\text { LR test } \\
p \text { value }\end{array}$ \\
\hline No. of sampled lymph nodes per increments of $10^{\mathrm{a}}$ & $0.79(0.58,1.08)$ & 0.129 & $0.82(0.57,1.17)$ & 0.266 \\
\hline T category & & $<0.001$ & & 0.129 \\
\hline T1-T2 & 1 (reference) & & 1 (reference) & \\
\hline $\mathrm{T} 3$ & $1.69(0.94,3.03)$ & & $1.84(0.55,6.15)$ & \\
\hline $\mathrm{T} 4$ & $3.38(1.79,6.40)$ & & $2.64(0.78,8.99)$ & \\
\hline Tumor location & & 0.568 & & 0.716 \\
\hline Right colon & 1 (reference) & & 1 (reference) & \\
\hline Transverse colon & $0.89(0.55,1.46)$ & & $0.79(0.47,1.32)$ & \\
\hline Descending colon & $0.97(0.39,2.42)$ & & $1.44(0.57,3.66)$ & \\
\hline Sigmoid colon & $0.70(0.45,1.10)$ & & $0.81(0.50,1.31)$ & \\
\hline Rectosigmoid & $0.82(0.44,1.53)$ & & $0.62(0.31,1.26)$ & \\
\hline Other/double & $0.96(0.23,3.93)$ & & $0.67(0.15,2.91)$ & \\
\hline $\mathrm{R} 2$ & $5.83(0.79,42.81)$ & & $0.61(0.08,4.94)$ & \\
\hline Age per 10 years & $1.46(1.23,1.74)$ & 0.001 & $1.68(1.38,2.03)$ & $<0.001$ \\
\hline Gender & & 0.192 & & 0.031 \\
\hline Females & 1 (reference) & & 1 (reference) & \\
\hline Males & $1.26(0.89,1.77)$ & & $1.52(1.04,2.23)$ & \\
\hline TNM stage & & $<0.001$ & & $<0.001$ \\
\hline I & 1 (reference) & & 1 (reference) & \\
\hline II & $1.61(0.82,3.18)$ & & $0.91(0.23,3.69)$ & \\
\hline III & $2.07(1.05,4.12)$ & & $1.49(0.39,5.66)$ & \\
\hline IV & $10.50(4.94,22.32)$ & & $9.26(2.15,39.85)$ & \\
\hline Hospital & & 0.390 & & 0.169 \\
\hline AHUS & 1 (reference) & & 1 (reference) & \\
\hline SUS & $1.06(0.71,1.60)$ & & $0.72(0.46,1.14)$ & \\
\hline HDS & $1.34(0.87,2.07)$ & & $0.62(0.37,1.03)$ & \\
\hline
\end{tabular}

$H R$ hazard ratio; CI confidence interval; LR likelihood ratio; SUS Stavanger University Hospital; HDS Haraldsplass Deaconal Hospital; AHUS Akershus University Hospital

${ }^{a}$ Analyses based on 258 patients because of lack of specified number of lymph nodes

stage III versus I-II were significant in the multivariate analysis. For stage III patients, the 5-year OS was 58.1\%. In one hospital, the 5-year OS for stage III was worse with $47.8 \%$. In the multivariate analysis, however, when adjusted for hospital, there was no significant survival difference. A recently published international multicenter study of a colorectal population [10] reported an identical OS of $58.8 \%$ for patients treated in 2000-2002. Others have found a 5-year OS of $90.7-96.3 \%$ for stage II and $64.6-71.7 \%$ for stage III using radical surgical procedures [2]. Thus, we consider our figures to show room for improvement, although where improvement may be best realised is debatable.

An advanced stage may theoretically be better treated with more radical surgery even though the presence of skip lesions in rare instances may hardly explain this [11]. Radical or complete mesocolic excision has been shown to increase both the absolute lymph node harvest and prognosis for the patients [2, 3]. However, it has been contested that patients will benefit from more radical surgery in advanced cases [12]. In a Swedish populationbased retrospective study [13], a median number of six lymph nodes were detected in the specimens from 1,856 patients operated between 1996 and 2000. The patients in that study had a high local recurrence rate of $11.5 \%$. Locations in the right flexure or left colon were independent risk factors for outcome. There were a very low number of nodes in the specimens from the left colon, whereas in the right flexure tumors, the lymph node count was not inferior. In both instances, the feeding vessel areas were not divided completely, i.e., the inferior mesenteric artery proximally and the root of the medial colic artery. In a population-based study from The Netherlands by Kelder and co-workers, the median lymph node harvest was six and in only $21 \%$ of the specimens were 12 or more nodes examined [14]. Thus, we consider that the principle of radical colon surgery may have been violated in these studies when tumors were in those locations. More 


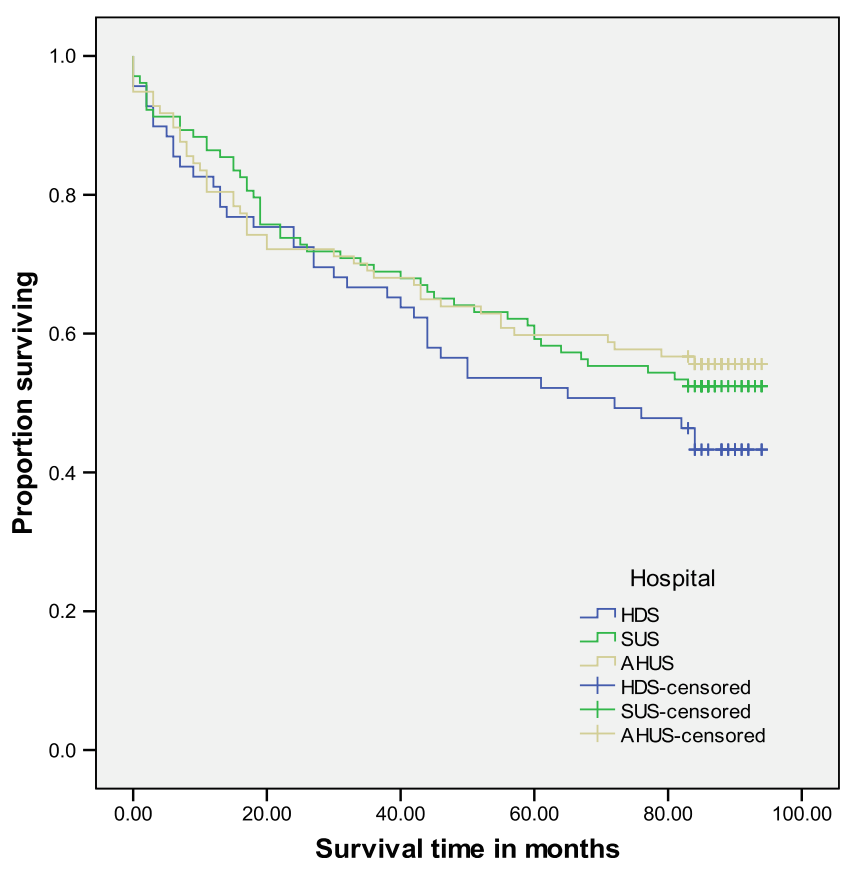

Fig. 3 Kaplan-Meier survival curves for 269 patients resected for colon cancer in three Norwegian hospitals in 2000 according to hospital (log-rank test $p=0.372$ )

radical surgery for colon cancer has been recommended in reports from the USA, Europe, and Japan [2, 15, 16]. A retrospective national report based on a small number with supposedly radical colon surgery found that this approach significantly increased survival compared with

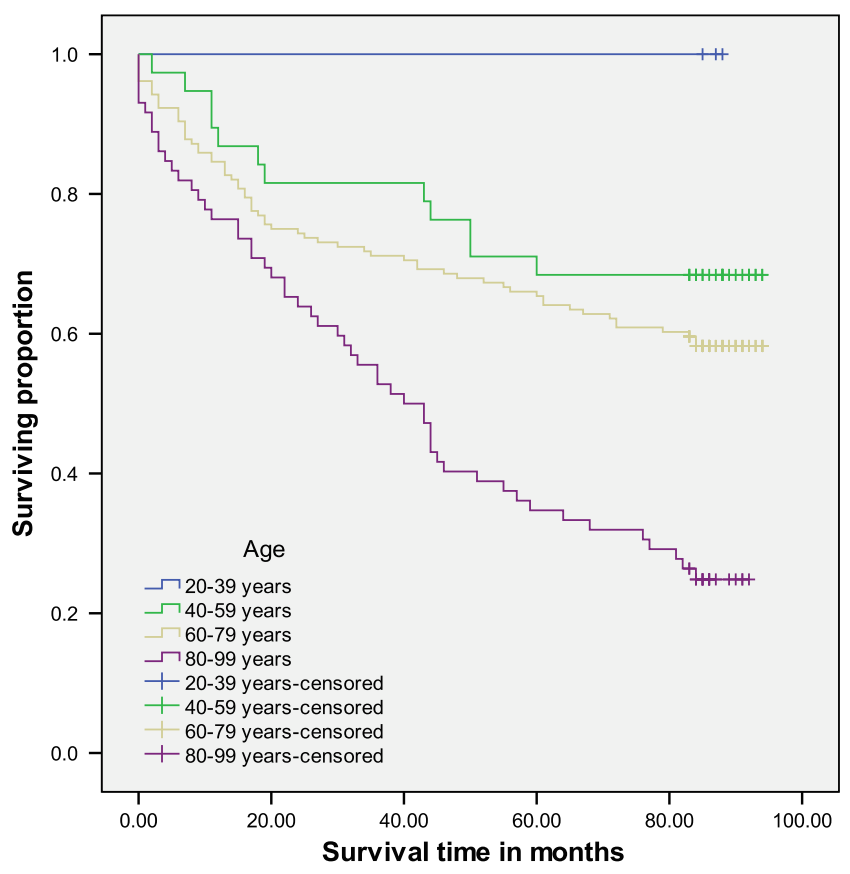

Fig. 4 Kaplan-Meier survival curves for 269 patients resected for colon cancer in three Norwegian hospitals in 2000 according to age (log-rank test $p<0.001$ )

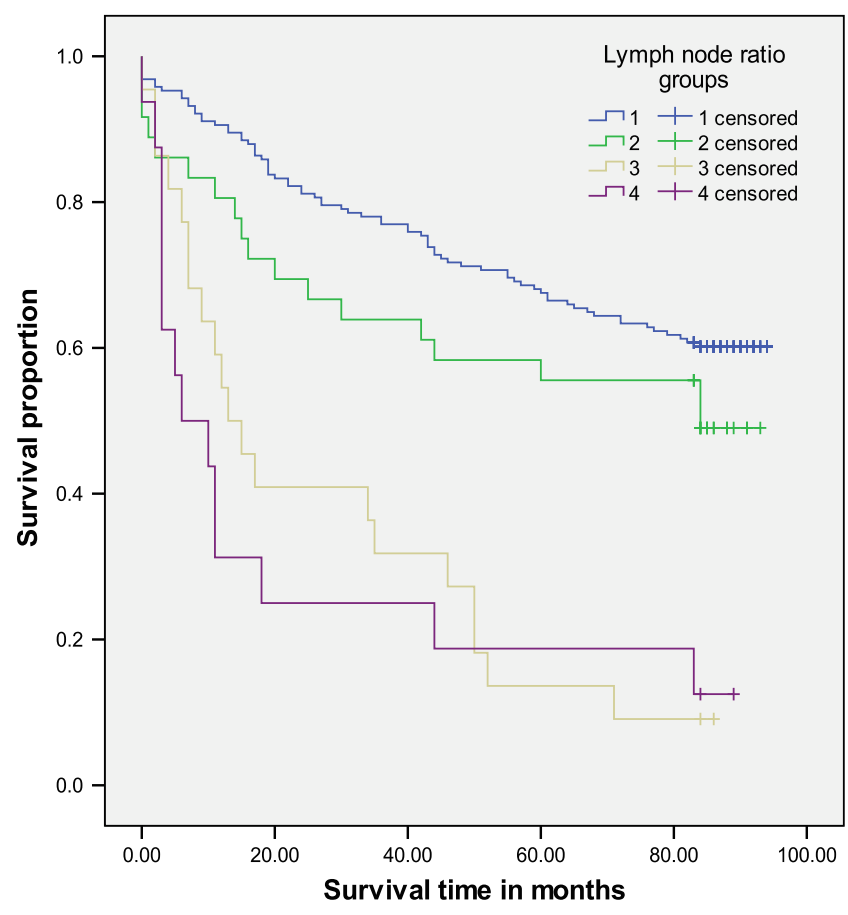

Fig. 5 Kaplan-Meier survival curves for 93 patients resected for colon cancer in three Norwegian hospitals in 2000 according to lymph node ratio groups: $<0.25$ (group 1), $0.25-0.5$ (group 2), $0.51-0.75$ (group 3), and $>0.75$ (group 4) (log-rank test $p<0.001$ )

a much larger and older group subject to a "standard" procedure [17].

The number of lymph nodes may be seen only as a surrogate marker for the extent of surgery without a proper

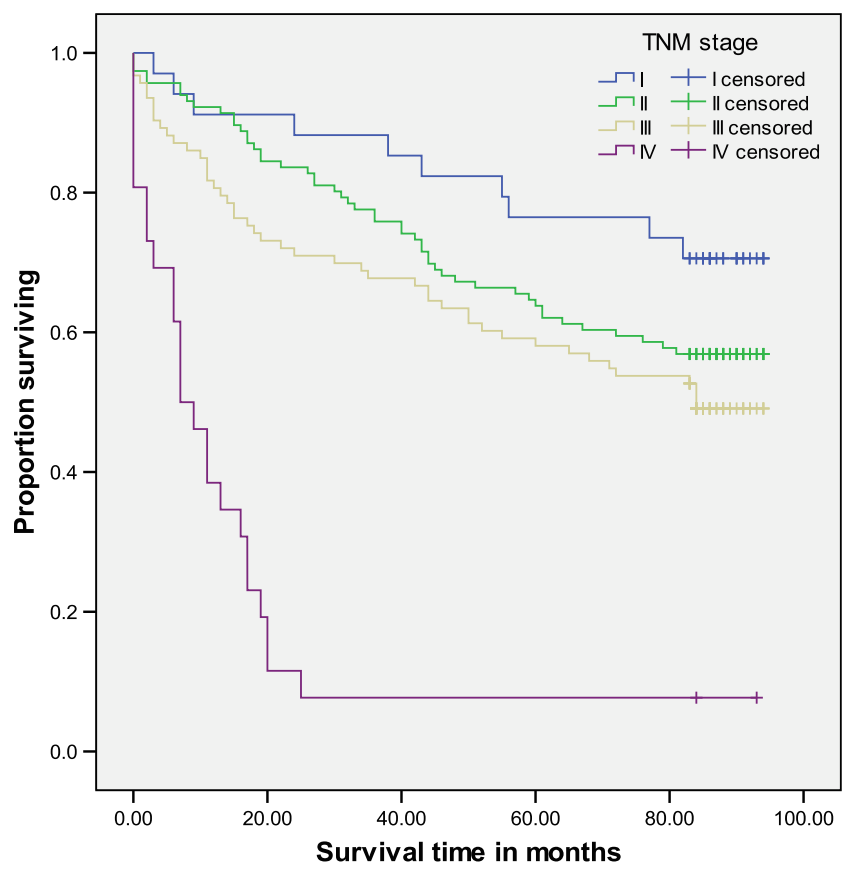

Fig. 6 Kaplan-Meier survival curves for 269 patients resected for colon cancer in three Norwegian hospitals in 2000 according to TNM stage (log-rank test $p<0.001$ ) 
oncologic explanation for the importance of a large harvest $[2,3]$. The node count has been correlated to survival both for stage II and III disease [2, 18]. The oncologic explanation is particularly lacking for stage II tumors [12]. The Ontario Cancer Registry study [19] showed better survival with a lymph node harvest of more than ten lymph nodes. Increasing the number even more did not improve survival. In contrast, there is good evidence reported by others that increasing the total number of lymph nodes increases survival significantly $[2,4]$. In one study, a mean harvest of more than 28 lymph nodes was reported [2]. Data from the SEER database demonstrated that a cutoff value of 15 was useful, and perhaps, there is an inherent limit to the number of nodes necessary to achieve this effect on survival [20]. Nevertheless, the hypothesis that a larger (negative) lymph node yield is beneficial is contradicted even from highly rated institutions [21]. Only $41 \%$ of our patients had more than 12 nodes detected in the specimen. In the univariate analysis, one of the hospitals achieved a significantly better survival with a harvest of more than 12 lymph nodes. However, no significant survival benefit was found with harvest of more than 12 lymph nodes in the multivariate analysis. Several confounding factors may have been present [21, 22]. Many pathologists were involved in this trial even though the specimen handling was supposed to be equal. In a recent study, the pathologist was found to be the dependent factor in lymph node harvest in multivariate analysis, not the operating surgeon [6]. The overall poor lymph node harvest may also indicate that more extensive surgery is one way to improve outcome as found in one of the hospitals. It may be speculated that the poorer outcome in the other two hospitals may have levelled out any benefit by an improved lymph node harvest, i.e., more radical surgery. The power of the study may have concealed such a result [21].

Patients below 75 years were given FLV chemotherapy, and staging was considered important for that reason. For proper staging of colon cancer, the minimum number of lymph nodes needed has been somewhat arbitrarily suggested as 12 by a National Cancer Institute expert panel [15]. Although some authors [14, 18] have concluded with stage migration as an explanation for an increased survival benefit, other studies have shown that detection of positive nodes beyond six or seven lymph nodes examined had no effect on staging [19, 23]. Thus, stage migration is debatable and should not be taken for granted [24]. Patient and tumor factors may also contribute to a variable lymph node presence [18]. Doubtless, a standardized surgical approach in cooperation with a dedicated pathology service is necessary if a minimum number of nodes shall be found and consequently help in outcome assessment. The mean number of lymph nodes in our series was 10.3. Therefore, under-staging was not considered important in our study
[24]. The share of stage III tumors equalled that reported by others from large cohorts [12].

Studies have shown that the LNR is an independent and better marker than $\mathrm{pN}+$ for survival [25]. In our study, LNR was highly significant for OS when adjusted for hospitals in the multivariate analysis. Five-year OS varied from $83.5 \%$ in LNR group 1, 63.3\% in LNR 2, to $18.8 \%$ in LNR group 3 . According to Wang et al. [26, 27], the prognostic effect of LNR did not depend on the total number of lymph nodes nor on the number of positive nodes. In contrast, Berger et al. [25] found that LNR was not a significant prognostic indicator with less than ten examined nodes but became highly significant for OS and disease-free survival with more than ten lymph nodes harvested. A Mayo Clinic study [21] found a positive correlation between the number of positive lymph nodes and survival but did not analyze the effect of LNR. Fifty-eight percent of our stage III patients had less than 12 lymph nodes examined. Still, we found a significant survival difference of $44.5 \%$ between LNR group 2 and 3 and $65.3 \%$ between group 1 and 4 . A study from New Zealand [22] found that both the absolute number of lymph nodes retrieved up to 16 , as well as the LNR, were important for prognosis. The share of stage III compared to stage II cancers in their patients amounted to $54.9 \%$, higher than in most other reports. It seems obvious that a large negative lymph node yield will down-regulate LNR, but the importance of this with regard to outcome may need to be examined in more detail.

Another national report of colon cancer from a single institution found that an emergency operation, some colon locations, blood transfusion of more than two units, old age, and TNM stage were negative predictive factors [28]. No information about lymph node harvest was given. We did not study the effect of blood transfusion, and emergency operations were not separated from the rest partly because they were few, i.e., $15 \%$ reported by Sjo et al. [28], and the definition may be debatable. Information about tumor obstruction or perforation would be more appropriate in our opinion. The different colon locations found to be statistically significant (transverse, left flexure, and descending colon) were not so in our multivariate analysis. We suspect that this is partly because they were too few, 20\%, to make an impact [28].

Old age was another adverse factor in our study. The overall in-hospital mortality in our series was $5 \%$. Even though the number of urgently operated patients was small in this series, as expected, this small group had a higher mortality of $12.5 \%$ compared to $4.5 \%$ in the elective patients. Severe co-morbidities in old age may have contributed to these figures as has been reported by others [29]. However, it should be possible to set an optimal target of $<3 \%$ in elective cases [2]. The average age of our study population was 71 years and that may be older than in 
series of selected patients. The average age of men and women in our country for those that have reached the age of 62 (earliest OAP retirement age) is 81 and 85 years. To circumvent the analytic problem of age, Sjo et al. [28] used relative survival. Thus, their survival figures improved from $62 \%$ actuarial survival to $74 \%$ for women and $79 \%$ for men. The method is cumbersome, as it necessitates life tables to calculate this for every patient year. Three-year disease-free survival has been shown to parallel overall 5year survival [30]. However, it requires close follow-up with CT instead of the conventional ultrasonography and chest X-ray examinations. Close follow-up may even result in better treatment of metastases according to Japanese results [31].

\section{Conclusion}

Only $41 \%$ had a lymph node harvest of 12 or more lymph nodes, and although this influenced OS in one hospital, it did not overall. The lymph node ratio was significant for stage III patients. More radical surgery may increase the lymph node yield, but if this has the potential to increase overall survival in our patients remains to be seen in the prospective registry. Mortality should be kept low with adequate assessment and treatment of co-morbidities as well as meticulous surgery to avoid complications.

Acknowledgment The study was supported by a grant from the Western Norway Health Authority, the University of Bergen and Haraldsplass Deaconal Hospital. Cand. med. Malte Schmidt helped organise data.

Open Access This article is distributed under the terms of the Creative Commons Attribution Noncommercial License which permits any noncommercial use, distribution, and reproduction in any medium, provided the original author(s) and source are credited.

\section{References}

1. (2007) Cancer in Norway. Available at http://www.kreftregisteret. no

2. Hohenberger W, Weber K, Matzel K, Papadopoulos T, Merkel S (2009) Standardized surgery for colonic cancer: complete mesocolic excision and central ligation - technical notes and outcome. Colorectal Dis 11(4):354-364, discussion 364-355

3. Hohenberger W, Reingruber B, Merkel S (2003) Surgery for colon cancer. Scand J Surg 92(1):45-52

4. Le Voyer TE, Sigurdson ER, Hanlon AL, Mayer RJ, Macdonald JS, Catalano PJ, Haller DG (2003) Colon cancer survival is associated with increasing number of lymph nodes analyzed: a secondary survey of intergroup trial INT-0089. J Clin Oncol 21 (15):2912-2919

5. Prandi M, Lionetto R, Bini A, Francioni G, Accarpio G, Anfossi A, Ballario E, Becchi G, Bonilauri S, Carobbi A, Cavaliere P, Garcea D, Giuliani L, Morziani E, Mosca F, Mussa A, Pasqualini M, Poddie D, Tonetti F, Zardo L, Rosso R (2002) Prognostic evaluation of stage B colon cancer patients is improved by an adequate lymphadenectomy: results of a secondary analysis of a large scale adjuvant trial. Ann Surg 235(4):458-463

6. Evans MD, Barton K, Rees A, Stamatakis JD, Karandikar SS (2007) The impact of surgeon and pathologist on lymph node retrieval in colorectal cancer and its impact on survival for patients with Dukes' stage B disease. Colorectal Dis 10:157164

7. Kaplan E, Meier P (1958) Nonparametric estimation from incomplete observations. Am Stat Assoc 53:457-481

8. Mantel N (1966) The log rank test. Evaluation of survival data and two new rank order statistics arising in its consideration. Cancer Chemother Rep 50:113-170

9. Cox D (1972) Regression models and life tables. J R Stat Soc B 34:187-220

10. Coleman M, Forman D, Bryant H, Butler J, Rachet B, Maringe C, Nur U, Tracey E, Coory M, Hatcher J, McGahan C, Turner D, Marrett L, Gjerstorff M, Johannesen T, Adolfsson J, Lambe M, Lawrence G, Meechan D, Morris E, Middleton R, Steward J, Richards M (2010) Cancer survival in Australia, Canada, Denmark, Norway, Sweden, and the UK, 1995-2007 (the International Cancer Benchmarking Partnership): an analysis of population-based cancer registry data. Lancet 377:127-138

11. Merrie AE, Phillips LV, Yun K, McCall JL (2001) Skip metastases in colon cancer: assessment by lymph node mapping using molecular detection. Surgery 129(6):684-691

12. Rosenberg R, Engel J, Bruns C, Heitland W, Hermes N, Jauch KW, Kopp R, Pütterich E, Ruppert R, Schuster T, Friess H, Hölzel D (2010) The prognostic value of lymph node ratio in a population-based collective of colorectal cancer patients. Ann Surg 251(6):1070-1078

13. Sjövall A, Granath F, Cedermark B, Glimelius B, Holm T (2006) Loco-regional recurrence from colon cancer: a population-based study. Ann Surg Oncol 14(2):432-440

14. Kelder W, Inberg B, Schaapveld M, Karrenbeld A, Grond J, Wiggers T, Plukker JT (2009) Impact of the number of histologically examined lymph nodes on prognosis in colon cancer: a population-based study in the Netherlands. Dis Colon Rectum 52(2):260-267

15. Nelson H, Petrelli N, Carlin A, Couture J, Fleshman J, Guillem J, Miedema B, Ota D, Sargent D (2001) Guidelines 2000 for colon and rectal cancer surgery. J Natl Cancer Inst 93(8):583596

16. Muto T, Kotake K, Koyama Y (2001) Colorectal cancer statistics in Japan: data from JSCCR registration, 1974-1993. Int J Clin Oncol 6(4):171-176

17. Ovrebo K, Rokke O (2009) Extended lymph node dissection in colorectal cancer surgery. Reliability and reproducibility in assessments of operative reports. Int J Colorectal Dis 25(2):213222

18. Hsu CW, Lin CH, Wang JH, Wang HT, Ou WC, King TM (2009) Factors that influence 12 or more harvested lymph nodes in earlystage colorectal cancer. World J Surg 33(2):333-339

19. Bui L, Rempel E, Reeson D, Simunovic M (2006) Lymph node counts, rates of positive lymph nodes, and patient survival for colon cancer surgery in Ontario, Canada: a population-based study. J Surg Oncol 93(6):439-445

20. Chen SL, Bilchik AJ (2006) More extensive nodal dissection improves survival for stages I to III of colon cancer: a populationbased study. Ann Surg 244(4):602-610

21. Tsikitis V, Larson D, Wolff B, Kennedy G, Diehl N, Qin R, Dozois E, Cima R (2009) Survival in stage III colon cancer is independent of the total number of lymph nodes retrieved. J Am Coll Surg 208(1):42-47

22. Vather R, Sammour T, Kahokehr A, Connolly AB, Hill AG (2009) Lymph node evaluation and long-term survival in stage ii 
and stage III colon cancer: a national study. Ann Surg Oncol 16 (3):585-593

23. Baxter NN, Ricciardi R, Simunovic M, Urbach DR, Virnig BA (2010) An evaluation of the relationship between lymph node number and staging in pT3 colon cancer using population-based data. Dis Colon Rectum 53(1):65-70

24. Søndenaa K, Storli K (2009) Increased lymph node retrieval in colon cancer did not change Dukes staging. World J Surg 33:S36, abstract ID: 0090

25. Berger AC, Sigurdson ER, LeVoyer T, Hanlon A, Mayer RJ, Macdonald JS, Catalano PJ, Haller DG (2005) Colon cancer survival is associated with decreasing ratio of metastatic to examined lymph nodes. J Clin Oncol 23(34):8706-8712

26. Wang J, Hassett JM, Dayton MT, Kulaylat MN (2008) Lymph node ratio: role in the staging of node-positive colon cancer. Ann Surg Oncol 15(6):1600-1608

27. Wang J, Kulaylat M, Rockette H, Hassett J, Rajput A, Dunn KB, Dayton M (2009) Should total number of lymph nodes be used as a quality of care measure for stage III colon cancer? Ann Surg 249 (4):559-563
28. Sjo OH, Lunde OC, Nygaard K, Sandvik L, Nesbakken A (2008) Tumour location is a prognostic factor for survival in colonic cancer patients. Colorectal Dis 10(1):33-40

29. Iversen LH, Bülow S, Christensen IJ, Laurberg S, Harling H, Danish Colorectal Cancer Group (2008) Postoperative medical complications are the main cause of early death after emergency surgery for colonic cancer. Br J Surg 95:1012-1019

30. Sargent DJ, Wieand HS, Haller DG, Gray R, Benedetti JK, Buyse M, Labianca R, Seitz JF, O’Callaghan CJ, Francini G, Grothey A, O'Connell M, Catalano PJ, Blanke CD, Kerr D, Green E, Wolmark N, Andre T, Goldberg RM, De Gramont A (2005) Disease-free survival versus overall survival as a primary end point for adjuvant colon cancer studies: individual patient data from 20,898 patients on 18 randomized trials. J Clin Oncol 23 (34):8664-8670

31. Kobayashi H, Mochizuki H, Sugihara K, Morita T, Kotake K, Teramoto T, Kameoka S, Saito Y, Takahashi K, Hase K, Oya M, Maeda K, Hirai T, Kameyama M, Shirouzu K, Muto T (2007) Characteristics of recurrence and surveillance tools after curative resection for colorectal cancer: a multicenter study. Surgery 141(1):67-75 